\title{
Dangerous drug interactions leading to hemolytic uremic syndrome following lung transplantation
}

\author{
Haralabos Parissis ${ }^{1 *}$, Kate Gould², John Dark ${ }^{2}$
}

\begin{abstract}
Background: To report our experience of a rather uncommon drug interaction, resulting in hemolytic uremic syndrome (HUS).

Methods: Two consecutive cases of hemolytic uremic syndrome were diagnosed in our service. In both patients the use of macrolides in patients taking Tacrolimus, resulted in high levels of Tacrolimus.

Results: The first patient was a 48 years old female with Bilateral emphysema. She underwent Single Sequential Lung Transplantation. She developed reperfusion injury requiring prolonged stay. Tacrolimus introduced (Day 51). The patient remained well up till 5 months later; Erythromycin commenced for chest infection. High Tacrolimus levels and a clinical diagnosis of HUS were made. She was treated with plasmapheresis successfully. The second case was a 57 years old female with Emphysema \& A1 Antithrypsin deficiency. She underwent Right Single Lung Transplantation. A2 rejection with mild Obliterative Bronchiolitis diagnosed 1 year later and she switched to Tacrolimus. She was admitted to her local Hospital two and a half years later with right middle lobe consolidation. The patient commenced on amoxicillin and clarithromycin. Worsening renal indices, high Tacrolimus levels, hemolytic anemia \& low Platelets were detected. HUS diagnosed \& treated with plasmapheresis.

Conclusions: There are 21 cases of HUS following lung transplantation in the literature that may have been induced by high tacrolimus levels. Macrolides in patients taking Cyclosporin or Tacrolimus lead to high levels. Mechanism of action could be glomeruloconstrictor effect with reduced GFR increased production of Endothelin-1 and increased Platelet aggregation.
\end{abstract}

\section{Introduction}

Extensive clinical use has confirmed that tacrolimus is a key option for immunosuppression after transplantation [1-3]. Tacrolimus as primary immunosuppressant for lung transplant recipient is associated with similar survival and reduction in acute rejection episodes compare with cyclosporine [4].

Haemolytic uraemic syndrome due to cyclosporin or tacrolimus in a lung transplant population is rare. Up to this year there were only few cases of tacrolimus induced haemolytic uraemic syndrome in lung transplant recipients, has been reported.

Out of 680 heart transplants, 65 heart lung transplantations and 378 lung transplantations since the beginning the transplant program, we identified two cases of

\footnotetext{
* Correspondence: hparissis@yahoo.co.uk

'Cardiothoracic Department, Royal Victoria Hospital, Grosvernor Rd, Belfast, BT12 6BA, Nothern Ireland

Full list of author information is available at the end of the article
}

tacrolimus induced haemolytic uraemic syndrome $(0.178 \%)$. Both cases were associated with high tacrolimus levels in a background of macrolide administration.

\section{Case 1}

The first reported case was a 48 years old female that had suffered bilateral severe emphysema. She underwent single sequential lung transplantation. Post operatively she developed reperfusion injury requiring prolonged intensive care unit stay.

She underwent a tracheostomy at the seventh post operative day and an open lung biopsy at the ninth post operative day. The twelfth post operative day she underwent a Laparotomy due to acute abdomen. She was eventually transferred to the ward the $38^{\text {th }}$ post operative day. The baseline urea was $22 \mathrm{mmol} / \mathrm{L}$ and Creatinine $250 \mathrm{mmol} / \mathrm{L}$. She was switched (day 52) to tacrolimus $1 \mathrm{mg}$ twice daily due to hirsutism. Following hospital discharge she remained well up to four months 


\section{urea}

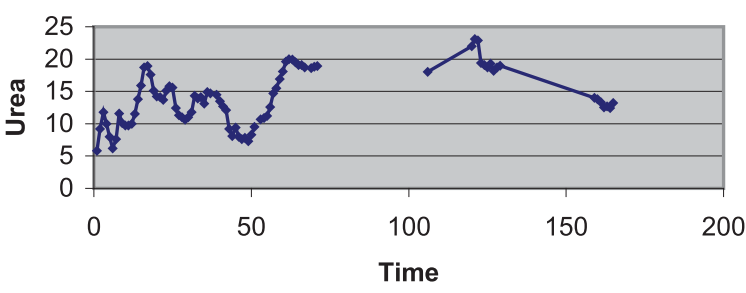

Creatinine Levels

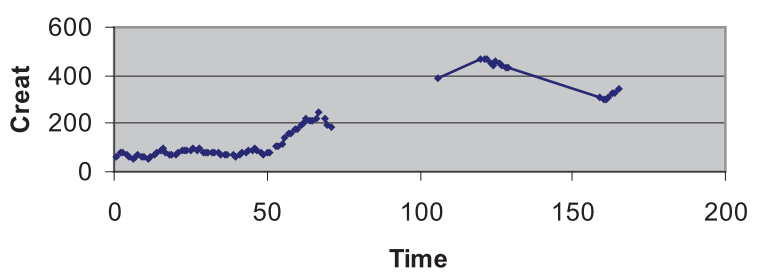

Tacrolimus Levels

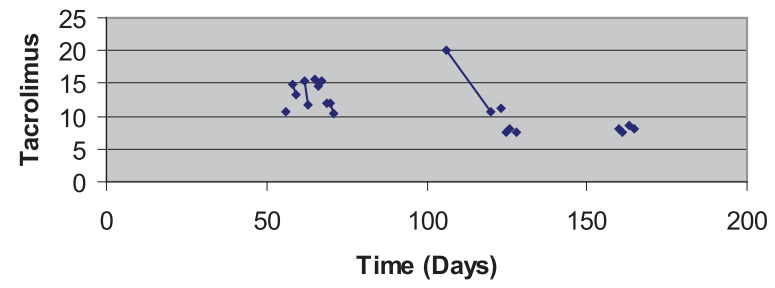

Figure 1 High Tacrolimus levels corresponding with worsening renal indices (Case 1)

where she developed a chest infection and treated with erythromycin. She was admitted to a local hospital (day 120) with worsening clinical picture, uremia (urea 24 $\mathrm{mmol} / \mathrm{L}$ and Creatinine $490 \mathrm{mmol} / \mathrm{L}$ ) hemolytic anemia, thrombocytopenia and trough tacrolimus levels of 21 $\mathrm{ng} / \mathrm{ml}$ (normal 5-15 ng/ml). See Figure 1

Clinical diagnosis of HUS was made. She was treated with plasmapheresis (plasma exchange) daily until the platelet count normalized 8 days later.

\section{Case 2}

The second reported case was a 57 years old, female with a clinical diagnosis of severe emphysema and A1 Antithrypsin deficiency.

She underwent right single lung transplantation. She was discharged home on day 21 st. She had a mild renal impairment with the urea of $15 \mathrm{mmol} / \mathrm{L}$ and creatinine of $220 \mathrm{mmol} / \mathrm{L}$. She was treated for singles one year later.

She had an A2 rejection 14 months later and a falling FEV1 from $1.26 \mathrm{~L}$ to $0.7 \mathrm{~L}$. CT chest (16 months later) showed features consisted with mild Obliterative Bronchiolitis. At this stage she was switched to Tacrolimus $3 \mathrm{mgr}$ BD. By the end of two years and four months following transplantation she has had no further deterioration in lung function and she was on tacrolimus $1 \mathrm{mgr} / 0.5 \mathrm{mgr}$, prednisolone $10 \mathrm{mgr}$ and azathioprine 75 mgr daily.

Unfortunately the same period she developed a colonic perforation due to diverticular disease and had a colostomy.

Two years and seven months following her transplantation she was admitted to her local hospital with right side chest pain \& breathlessness and right middle lobe consolidation and was treated as pneumonia with amoxicillin and clarithromycin.

The patient was transferred to our service 7 days later with unresolving pneumonia and worsening renal indices (urea from $14 \mathrm{mmol} / \mathrm{L}$ to $29 \mathrm{mmol} / \mathrm{L}$ and creatinine from $171 \mathrm{mmol} / \mathrm{L}$ to $235 \mathrm{mmol} / \mathrm{L}$ ). The Hemoglobin was $9.6 \mathrm{~g} / \mathrm{dL}$, WCC $9.7 \times 10^{3} / \mathrm{mm}^{3}$, Platelets $188.000 / \mathrm{mm}^{3}$, urea $28.8 \mathrm{mmol} / \mathrm{L}$, creatinine $239 \mathrm{mmol} /$ $\mathrm{L}$, total bilirubin $19 \mathrm{mmol} / \mathrm{L}$, with normal liver function tests. Arterial Blood Gases on 2 lt of Oxygen showed $\mathrm{Ph}: 7.27, \mathrm{PCO} 2: 4.0 \mathrm{KPa}, \mathrm{PO} 2: 10.7 \mathrm{KPa}, \mathrm{BE}:-12$. The tacrolimus level was $7.0 \mathrm{ng} / \mathrm{mL}$. She underwent bronchoscopy \& Bronchoalveolar lavage. D-Dimers were not elevated. The patient was allergic to dye therefore a CT pulmonary angiogram was not performed. The clinical picture was considered to be due to an underlying rejection and she was augmented with IV methylprednisolone.

- One day following admission:

Full Treatment for Pulmonary Embolism with tinzaparin. Dialysis was commenced for high Potassium: 6.3 $\mathrm{mmol} / \mathrm{L}$ and acidosis. High Tacrolimus Levels $>30 \mathrm{ng} /$ $\mathrm{mL}$ were also detected. Azothioprine and tacrolimus were stopped.

- Two days following admission:

Falling Haemoglobin to $8.4 \mathrm{~g} / \mathrm{dL}$, platelets $126.000 /$ $\mathrm{mm}^{3}$

- Three days following admission:

Episode of VT. Hb $8.2 \mathrm{~g} / \mathrm{dL}$, platelets $99.000 / \mathrm{mm}^{3}$, Tacrolimus level $28.6 \mathrm{ng} / \mathrm{mL}$ (see Figure 2)

- Four days following admission:

Haemoglobin $7.6 \mathrm{~g} / \mathrm{dL}$, platelets $75.000 / \mathrm{mm}^{3}$, Serum iron $16 \mathrm{mmol} / \mathrm{L}$ (normal 11-29 mmol/L), ferrittin 1571 $\mathrm{ng} / \mathrm{ml}$.

- Five days following admission:

Anaemia (Hb: $6.7 \mathrm{~g} / \mathrm{dL}$ ) \& Thrombocytopenia (Platelets: $\left.65.000 / \mathrm{mm}^{3}\right)$. Blood film showed fragmented red cells. The clotting screen was normal, LDH 1280 U/L, and heparine induced antibodies screen was negative. The diagnosis of HUS was made

- Six days following admission:

Plasmapheresis commenced ( $\mathrm{Hb}: 9.8 \mathrm{~g} / \mathrm{dL}$, platelets $52.000 / \mathrm{mm}^{3}$ )

- Seven days following admission: 


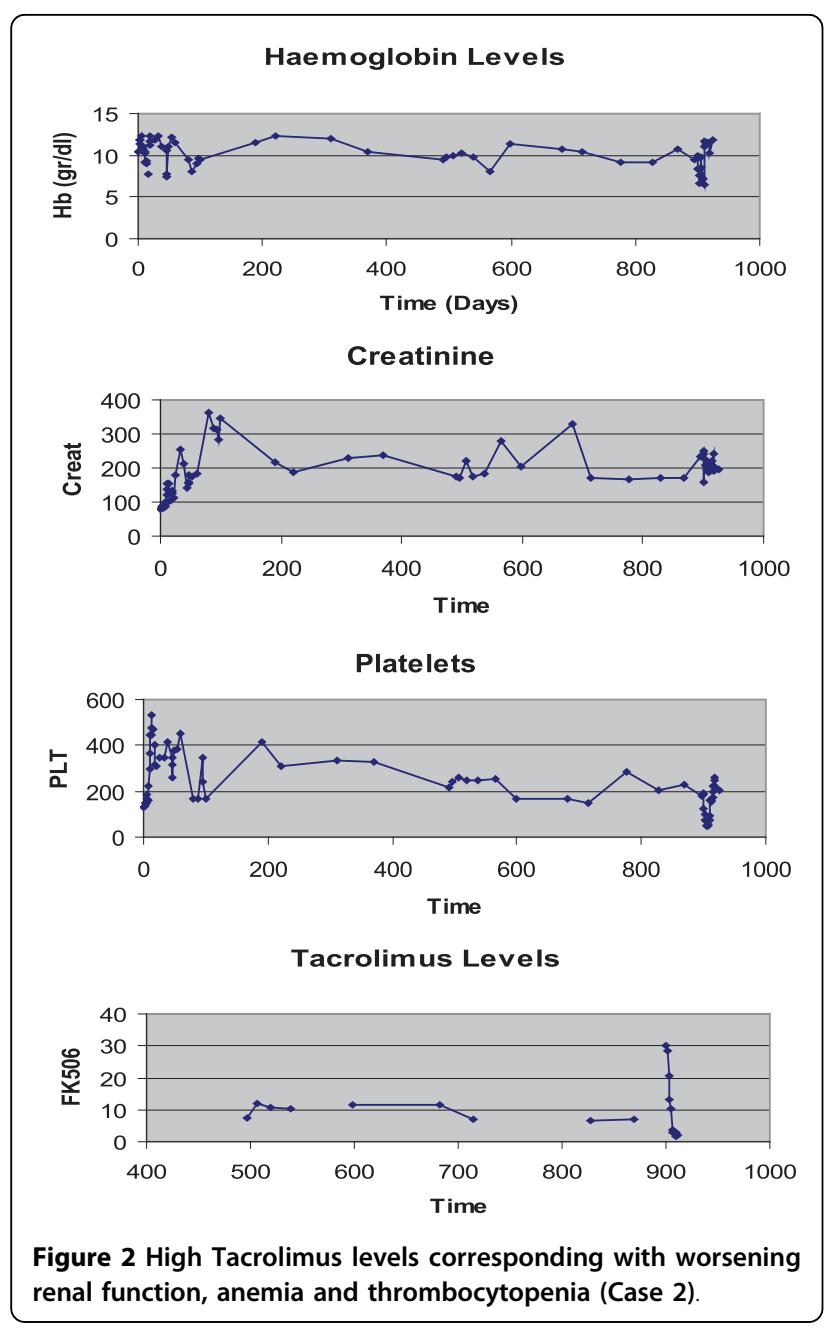

Plasma exchange continued, for the next 5 days. At this stage the patient's clinical picture improved and the platelet count has risen to $159.000 / \mathrm{mm}^{3}$. In the mean time the immunosuppressant regime had been changed to MMF and rapamycin.

\section{Discussion}

Thrombotic thrombocytopenic purpura- haemolytic uraemic syndrome is an inclusive term describing diverse symptoms of multiple etiologies with common features of thrombocytopenia, microangiopathic haemolytic anaemia, normal clotting screen and also renal, neurological and gastrointestinal involvement [5].

There are two principle mechanisms [5] by which drugs may cause HUS:

A dose related toxicity (eg. cyclosporin) whereby the onset is gradual and an immune mediated reaction (eg. clopidogrel) whereby the onset is explosive and re-exposure produces immediate recurrence. Infection per say is not a significant precipitating factor for post-transplant hemolytic uremic syndrome [5].

A total number of 91 cases of haemolytic uraemic syndrome in adult solid organ transplant recipients were reported by 1996 [6] 90\% renal 8\% Liver \& 2\% Heart -Lungs. $96 \%$ of the cases occurred within 1 year. In the majority of renal cases and all non-renal transplants HUS was attributed to the use of cyclosporin. Only 4 patients developed HUS while on tacrolimus, including 1 renal transplant recipient and 3 liver transplant recipients. Graft loss due to HUS occurred in $43 \%$ of renal transplant recipients. The overall mortality was $13 \%$.

Tacrolimus associated HUS first described by Schmidt et al [7] in a renal recipient in 1991. Until 1999 there were 21 cases reported of tacrolimus associated thrombotic microangiopathy. There were no lung transplant cases in this report.

Various studies have looked at the patient's demographics and also the incidence of HUS amongst transplant recipients [8], [9], [10]: tacrolimus-associated HUS is more frequent in females. The incidence of FK506associated thrombotic microangiopathy (TMA) is between $1 \%$ and $4.7 \%$ and the prevalence is between 0.14 and $0.7 \%$ [9].

Tacrolimus-associated HUS following lung transplantation was not reported in the literature up until 1999

Table 1 Literature review of Tacrolimus induced HUS following Lung Transplantation

\begin{tabular}{|c|c|c|c|c|c|c|c|c|}
\hline Case & $\begin{array}{l}\text { Age/ } \\
\text { Gender }\end{array}$ & disease & Time to HUS (months) & $\begin{array}{l}\text { Dose } \\
\mathrm{mgr} / \text { day }\end{array}$ & $\begin{array}{l}\text { Level } \\
\mathrm{ng} / \mathrm{mL}\end{array}$ & operation & References & year \\
\hline 1 & $60 / F$ & COAD & 9 & $6 / 6$ & 16.7 & LtLTx & $\begin{array}{l}\text { Myers J et al } \\
\text { (11) }\end{array}$ & 1999 \\
\hline 2 & $62 / M$ & emphysema & 30 & 6 & 16.3 & RtLTx & $\begin{array}{l}\text { Shitrit D et al } \\
(12)\end{array}$ & 2003 \\
\hline 3 & $56 / F$ & emphysema & 36 & Not reported & $\begin{array}{l}\text { Not } \\
\text { reported }\end{array}$ & LtLTx & $\begin{array}{l}\text { Boctor FN. } \\
\text { et al (13) }\end{array}$ & 2006 \\
\hline 4 & $48 / F$ & emphysema & 5 & $0.5 / 0.5$ & 20 & SSLTX & Own experience & 2003 \\
\hline 5 & $57 / F$ & emphysema & 19 & $1 / 0.5$ & $>30$ & RtLTx & Own experience & 2003 \\
\hline
\end{tabular}


[11]. Two more cases were subsequently published [12], [13]. Successful resolution of HUS was achieved following conversion from tacrolimus to cyclosporine.

Tacrolimus is a direct glomeruloconstrictor [14]. This effect is dose dependent [15]. It also reduces glomerular filtration rate and increases renal vascular resistance via Endothelin-1. The net effect is ischemia and endothelial cell injury. That triggers inflammation and platelet aggregation, resulting in thrombi and fibrin deposition.

Trough levels of tacrolimus were not predictive for the development of HUS however peak plasma levels of tacrolimus are usually never measured and these could correlate better with tacrolimus -associated HUS [15]. Moreover a reduction in the dose of tacrolimus correlates with an improvement in renal function in most patients [12], [14].

The diagnosis of tacrolimus -associated HUS in the two patients who are the subject of the present report, was supported by an overwhelming clinical picture and clinical follow up. In both patients, high tacrolimus levels were detected following administration of macrolides based antibiotics. They both went on to develop severe microangiopathic haemolysis, thrombocytopenia and renal impairment. They both treated with cessation of tacrolimus and required plasmapheresis, until the platelet count normalized.

All five reported cases in the literature (see Table 1) included patients suffered from emphysema. As to whether there is a relationship between emphysema/a-1 antitrypsin deficiency and the development of HUS in a background of tacrolimus toxicity remains to be seen.

In conclusion tacrolimus-associated HUS in the lung transplant population is an infrequent entity, and presents with insidious symptomatology requiring high index of suspicion. Furthermore macrolides in patients taking tacrolimus could potentially lead to high levels, with deleterious consequences.

\section{Competing interests}

The authors declare that they have no competing interests

\section{Authors' contributions}

$\mathrm{HP}$ conceived of the study, gathered the data and wrote the manuscript, KG made the diagnosis of HUS in those two cases, helped in the design of the study and participated in the sequence alignment, JD participated in the design and coordination and overlooked the progress of the manuscript and advised on valuable amendments. All authors read and approved the final manuscript.

\section{Consent}

Written informed consent was obtained from the patients for publication of those two case reports and accompanying figures. A copy of the written consent is available for review by the Editor-in-Chief of this journal.

\section{Author details}

${ }^{1}$ Cardiothoracic Department, Royal Victoria Hospital, Grosvernor Rd, Belfast, BT12 6BA, Nothern Ireland. ${ }^{2}$ Cardiothoracic Department, Freeman Hospital, High Heaton, Newcastle upon Tyne, NE7 7DN, UK.
Received: 5 June 2010 Accepted: 2 September 2010

Published: 2 September 2010

\section{References}

1. Scott LJ, McKeage K, Keam SJ, Plosker GL: Tacrolimus: a further update of its use in the management of organ transplantation. Drugs 2003, 63(12):1247-97.

2. Reichenspurner $\mathrm{H}$ : Overview of tacrolimus-based immunosuppression after heart or lung transplantation. J Heart Lung Transplant 2005, 24(2):119-30.

3. Keogh A: Calcineurin inhibitors in heart transplantation. $J$ Heart Lung Transplant 2004, 23(5 Suppl):S202-6.

4. Fan Y, Xiao YB, Weng YG: Tacrolimus versus cyclosporine for adult lung transplant recipients: a meta-analysis. Transplant Proc 2009, 41(5):1821-4.

5. Moake J: Thrombotic thrombocytopenia purpura (TTP) and other thrombotic microangiopathies. Best Pract Res Clin Haematol 2009, 22(4):567-76.

6. Singh N, Gayowski T, Marino IR: Hemolytic uremic syndrome in solidorgan transplant recipients. Transpl Int 1996, 9(1):68-75.

7. Schmidt RJ, Venkat KK, Dumler F: Hemolytic-uremic syndrome in a renal transplant recipient on FK 506 immunosuppression. Transplant Proc 1991 23(6):3156-7.

8. Lin CC, King KL, Chao YW, Yang AH, Chang CF, Yang WC: Tacrolimusassociated hemolytic uremic syndrome: a case analysis. J Nephrol 2003, 16(4):580-5.

9. Trimarchi HM, Truong LD, Brennan S, Gonzalez JM, Suki WN: FK506associated thrombotic microangiopathy: report of two cases and review of the literature. Transplantation 1999, 27;67(4):539-44.

10. Pham PT, Peng A, Wilkinson AH, Gritsch HA, Lassman C, Pham PC, Danovitch GM: Cyclosporine and tacrolimus-associated thrombotic microangiopathy. Am J Kidney Dis 2000, 36(4):844-50.

11. Myers JN, Shabshab SF, Burton NA, Nathan SD: Successful use of cyclosporine in a lung transplant recipient with tacrolimus-associated hemolytic uremic syndrome. J Heart Lung Transplant 1999, 18(10):1024-6.

12. Shitrit D, Starobin D, Aravot D, Fink G, Izbicki G, Kramer M: Tacrolimusinduced hemolytic uremic syndrome case presentation in a lung transplant recipient. Transplant Proc 2003, 35(2):627-8.

13. Boctor FN: Tacrolimus (FK506) associated thrombotic thrombocytopenic purpura/hemolytic uremic syndrome in lung transplant salvage with a plasmapheresis and cyclosporin. Egypt J Immunol 2006, 13(2):95-9.

14. Mercadal L, Petitclerc T, Assogba U, Beaufils H, Deray G: Hemolytic and uremic syndrome after heart transplantation. Am J Nephrol 2000, 20(5):418-20.

15. Galli FC, Damon LE, Tomlanovich SJ, Keith F, Chatterjee K, DeMarco T: Cyclosporine-induced hemolytic uremic syndrome in a heart transplant recipient. J Heart Lung Transplant 1993, 12(3):440-4.

doi:10.1186/1749-8090-5-70

Cite this article as: Parissis et al: Dangerous drug interactions leading to hemolytic uremic syndrome following lung transplantation. Journal of Cardiothoracic Surgery 2010 5:70.

\section{Submit your next manuscript to BioMed Central and take full advantage of:}

- Convenient online submission

- Thorough peer review

- No space constraints or color figure charges

- Immediate publication on acceptance

- Inclusion in PubMed, CAS, Scopus and Google Scholar

- Research which is freely available for redistribution 